\title{
Non-genetic health professionals' attitude towards, knowledge of and skills in discussing and ordering genetic testing for hereditary cancer
}

\author{
Kirsten F. L. Douma ${ }^{1}$ - Ellen M. A. Smets ${ }^{1}$ Dawn C. Allain ${ }^{2}$
}

Published online: 21 November 2015

(c) The Author(s) 2015. This article is published with open access at Springerlink.com

\begin{abstract}
Non-genetic health professionals (NGHPs) have insufficient knowledge of cancer genetics, express educational needs and are unprepared to counsel their patients regarding their genetic test results. So far, it is unclear how NGHPs perceive their own communication skills. This study was undertaken to gain insight in their perceptions, attitudes and knowledge. Two publically accessible databases were used to invite NGHPs providing cancer genetic services to complete a questionnaire. The survey assessed: sociodemographic attributes, experience in ordering hereditary cancer genetic testing, attitude, knowledge, perception of communication skills (e.g. information giving, decision-making) and educational needs. Of all respondents ( $\mathrm{N}=49$, response rate $11 \%$ ), most have a positive view of their own information giving (mean $=53.91$, range 13-65) and decision making skills (64-77\% depending on topic). NGHPs feel responsible for enabling disease and treatment related behavior (89-91\%). However, 20-30\% reported difficulties managing patients' emotions and did not see management of long-term emotions as their responsibility. Correct answers on knowledge questions ranged between 41 and $96 \%$. Higher knowledge was associated with more confidence in NGHPs' own communication skills $\left(\mathrm{r}_{\mathrm{s}}=.33\right.$, $p=0.03$ ). Although NGHPs have a positive view of their communication skills, they perceive more difficulties managing emotions. The association between less
\end{abstract}

Kirsten F. L. Douma

k.f.douma@amc.uva.nl

1 Department of Medical Psychology, Academic Medical Center/University of Amsterdam, P.O. Box 22660, 1100 DD Amsterdam, The Netherlands

2 Division of Human Genetics, The Ohio State University Wexner Medical Center, Columbus, OH, USA confidence in communication skills and lower knowledge level suggests awareness of knowledge gaps affects confidence. NGHPs might benefit from education about managing client emotions. Further research using observation of actual counselling consultations is needed to investigate the skills of this specific group of providers.

Keywords Communication skills · Cancer genetics . Doctor-patient communication - Knowledge

\section{Introduction}

Since the early 1990s the possibilities for DNA testing in cancer have rapidly expanded. Through the combination of pedigree risk assessment and genetic testing it can be determined whether a patient's personal or family history of cancer has an underlying hereditary cause. Genetic information about cancer is complex and involves understanding risks and inheritance patterns. Many individuals find such complex information difficult to understand [1, 2]. Explaining genetic information to patients or at-risk family members is demanding and has traditionally been carried out by trained medical geneticists and genetic counselors. Research shows that clinical geneticists and genetic counselors in general are well trained to provide genetic information [3]. Hence, they have an important role in providing the information in an understandable way.

Over the last decade, though, more genetic tests, especially in the United States, are being ordered by non-genetic health professionals, such as oncologists, gynecologists, and primary care providers $[4,5]$. The American Society of Clinical Oncology stressed that the burden on oncologists becomes greater in fully explaining issues surrounding cancer risks, including genetic risks. Also, they need to be 
prepared to order genetic tests themselves and to be responsible for appropriate follow-up care. Therefore, they need to know of recent genetic advances $[6,7]$. This level of preparedness is not only necessary for oncologists, but also for other health professionals caring for cancer patients.

The six-function medical communication model of de Haes and Bensing [8] states that medical communication should include (1) fostering the relationship, (2) gathering information, (3) information provision, (4) decision making, (5) enabling disease and treatment-related behavior, and (6) responding to emotions. Communication about cancer genetics requires all of these communication tasks. First, proper gathering of information is necessary to identify someone at high risk. Second, information provision must be adequate to inform patients and family members not only with basic information about heredity, but also about the most adequate treatment and/or preventive measures. Third, ordering a genetic test asks for adequate information exchange and (shared) decisionmaking. Fourth, motivational communication to enable patients to follow screening recommendations and undergo prophylactic surgery, when necessary, is an important task. Within all communication about genetic testing for cancer, emotions with regard to the test result and consequences for the patient and their family should be addressed.

Numerous studies have shown that non-genetic health professionals have insufficient knowledge of genetics, express educational needs and are generally unprepared to counsel their patients regarding genetic test results [9-14]. Also, family history taking $[15,16]$ and risk communication [17] are perceived as difficult tasks by non-geneticists. Inadequate genetic counseling and testing can lead to negative outcomes in patients and their families [18, 19]. However, not much is known about the attitude towards, knowledge of and communication skills in discussing and ordering genetic testing of non-genetic health professionals (NGHPs) who order genetic tests themselves.

The current study was undertaken to gain insight into the attitude, knowledge and skills of NGHPs who provide genetic testing. Investigating the perceptions of non-genetic health professionals about the communication process will provide insight in their perceived barriers and challenges to genetic counseling and testing. If deemed necessary this could aid in the development of an intervention to support and enhance their communication skills.

We also wondered if NGHPs are aware of their knowledge level. A study by Klitzman et al. [10] showed that internists who rated (subjectively) their knowledge as poor, and were uncomfortable ordering testing and counseling patients, still ordered genetic tests. Therefore, in this study we investigate if NGHPs' objective knowledge level is associated with their self-perceived information giving skills. We hypothesize that if there is an association this might point to awareness of limitations and thus more willingness to receive further education.

The primary research questions are:

1. How do NGHPs providing genetic testing perceive their own communication behavior (attitude, knowledge, skills) in cancer gene testing?

2. What education and/or training have NGHPs received with regard to communication about cancer gene testing and what are their needs in this regard?

3. What is the level of knowledge NGHPs have about cancer gene testing and is it associated with selfperceived information giving skills?

\section{Materials and methods}

\section{Study sample and procedures}

The Myriad Genetics Find a Healthcare Provider website (www.myriadtests.com/finddoc.php) and the National Cancer Institute (NCI) Cancer Genetics Services Directory (www.cancer/gov/cancertopics/genetics/directory) are publically accessible databases containing contact information for healthcare providers who have self-identified as cancer genetic service providers. At the time of this study, Myriad Genetic Laboratories was the sole provider of genetic testing for the BRCA1 and BRCA2 genes in the United States. The Find A Provider section on their website was a mechanism for patients to identify healthcare professionals in their communities who provided genetic testing. Listing on the website was completely voluntary and the list was managed by Myriad Genetic Laboratories. The database of the NCI lists professionals who provide services related to cancer genetics (cancer risk assessment, genetic counseling, genetic susceptibility testing, and others). Professionals must apply to be listed in this directory and must meet certain criteria. Inclusion in the directory does not imply an endorsement by the National Cancer Institute. Professionals listed are contacted yearly by the NCI through e-mail to verify and/or update their record information.

For this study, we utilized these databases, to identify our study population. Study eligibility was as follows: (1) healthcare professionals self-identified as providing cancer genetic services with contact information listed on the Myriad Genetics Find a Healthcare Provider or NCI Cancer Genetics Services Directory and (2) providers of care in one of four Midwest states (Ohio, Michigan, Indiana, and Kentucky). Individuals who met the eligibility criteria were sent a letter of invitation explaining the aim of the study along with a paper version of the survey and a return envelope. The letter of invitation also included a link to an online version of the survey. A reminder was sent after 
2 weeks. Completion and return of the study questionnaire implied consent. Health professionals who completed the survey and reported they were trained as master-degree genetic counselors, advanced practice nurses in genetics, or medical geneticists were excluded from data analysis.

Because of a low response rate we expanded the study to four more states (Texas, California, New York, and Massachusetts). The procedure was the same. However, this time a prize draw for two Amazon gift cards of fifty dollars and the possibility to receive a report about the results of the study were added, trying to increase the response rate.

The IRB of The Ohio State University approved the study.

\section{Measures}

\section{Questionnaire}

Questionnaire items assessed: (1) Sociodemographic characteristics, (2) Practice characteristics, (3) Information giving, (4) Decision-making, (5) Communication about disease and treatment related behaviors, (6) Managing emotions, (7) Education and (8) Knowledge. Table 1 shows the details of the measures used.

\section{Data analysis}

Descriptive statistics were used to describe the study sample. Sum scores were calculated for Information giving Skills perception (see $3 \mathrm{~b}$ in Table 1) and Objective knowledge (see $8 \mathrm{c}$ in Table 1). The total knowledge score was calculated by assigning one point for every correct answer (range 0-9). A mean correct knowledge score was calculated as the mean number of correct answers on the knowledge items. In addition, the percentage of correct answers for each item was analyzed.

We calculated reliability for the three subscales of the adapted Ideal Patient Autonomy Scale (IPAS) (see Table 1). Because alpha's are low, results for individual items are presented. Pearson' correlation was calculated for the association between the total score of Perception of Information giving skills and the Knowledge score. All analyses were carried out using IBM SPSS version 20.0. A $p$ value of .05 (two-sided) was considered significant.

\section{Results}

\section{Sample characteristics}

In the first mailing (summer 2013) 151 invitations were sent of which 17 were not delivered due to incorrect address (returned to sender). In the second mailing (April
2014), we sent out 366 invitations of which 70 returned for incorrect address. In total, we received 49 questionnaires (11\% response rate). One filled-in questionnaire was removed because of many missing values, four others were removed because they were filled in by participants specialized in genetic counseling or medical genetics. Table 2 displays the characteristics of the sample.

\section{Information giving}

NGHPs reported addressing most relevant topics when providing cancer genetic counseling. These topics included: benefits and limitations of close cancer surveillance (95\% always/frequently discuss this), sharing test results with family members (91\%), benefits and limitations of prophylactic surgery (89\%) and confidentiality and privacy $(89 \%)$. The possibility of a negative psychological reaction to genetic testing was least often discussed (73 vs. 89-95\%).

NGHPs positively perceived their own information giving skills with a mean score $53.91(\mathrm{SD}=6.8)$ on a scale of 13-65. Individual items showed that NGHPs found it most difficult to inform a patient about a variant test result: $16 \%$ (strongly) agreed, while $23 \%$ neither agreed or disagreed. Also, informing minority patients [14\% (strongly) agreed, $16 \%$ neither agreed nor disagreed] and lower educated patients [14\% (strongly) agreed, $27 \%$ neither agreed nor disagreed] was perceived as difficult by some. In addition, $14 \%$ found it difficult to ensure that patients understand the genetic test result $(27 \%$ neither agreed nor disagreed) and $14 \%$ found it difficult to inform a patient about a positive test result (11\% neither agreed nor disagreed).

\section{Decision-making}

On average, NHGPs' opinion was that patients know best regarding decisions about genetic testing [mean score is $3.92(\mathrm{SD}=0.50)]$ and patients should decide [mean score is $1.69(\mathrm{SD}=0.59)$ ]. Furthermore, opinions diverged as to patients' right not to pursue genetic testing [mean score is $2.77(\mathrm{SD}=0.80)]$. Table 3 shows the responses to the individual items of the adapted IPAS.

Figure 1 shows that $7-16 \%$ of NHGPs perceived communication tasks related to decision-making as difficult, depending on the task. They experienced most difficulties explaining the consequences of genetic testing for the patient as well as the family members.

\section{Enabling disease- and treatment related behavior}

Ninety-eight percent $(n=43)$ of NHGPs agreed that it was their responsibility to discuss preventive behaviors with 


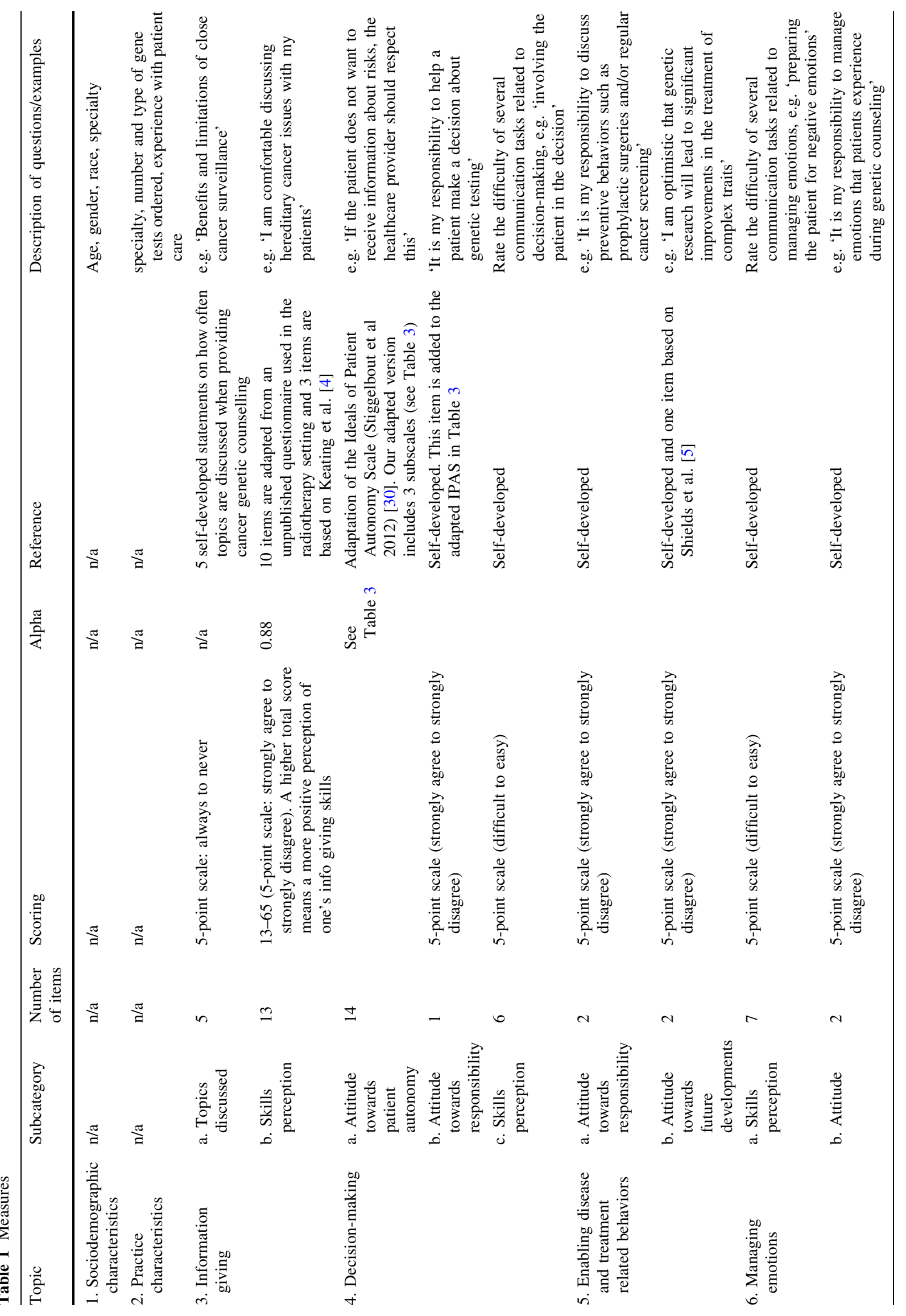




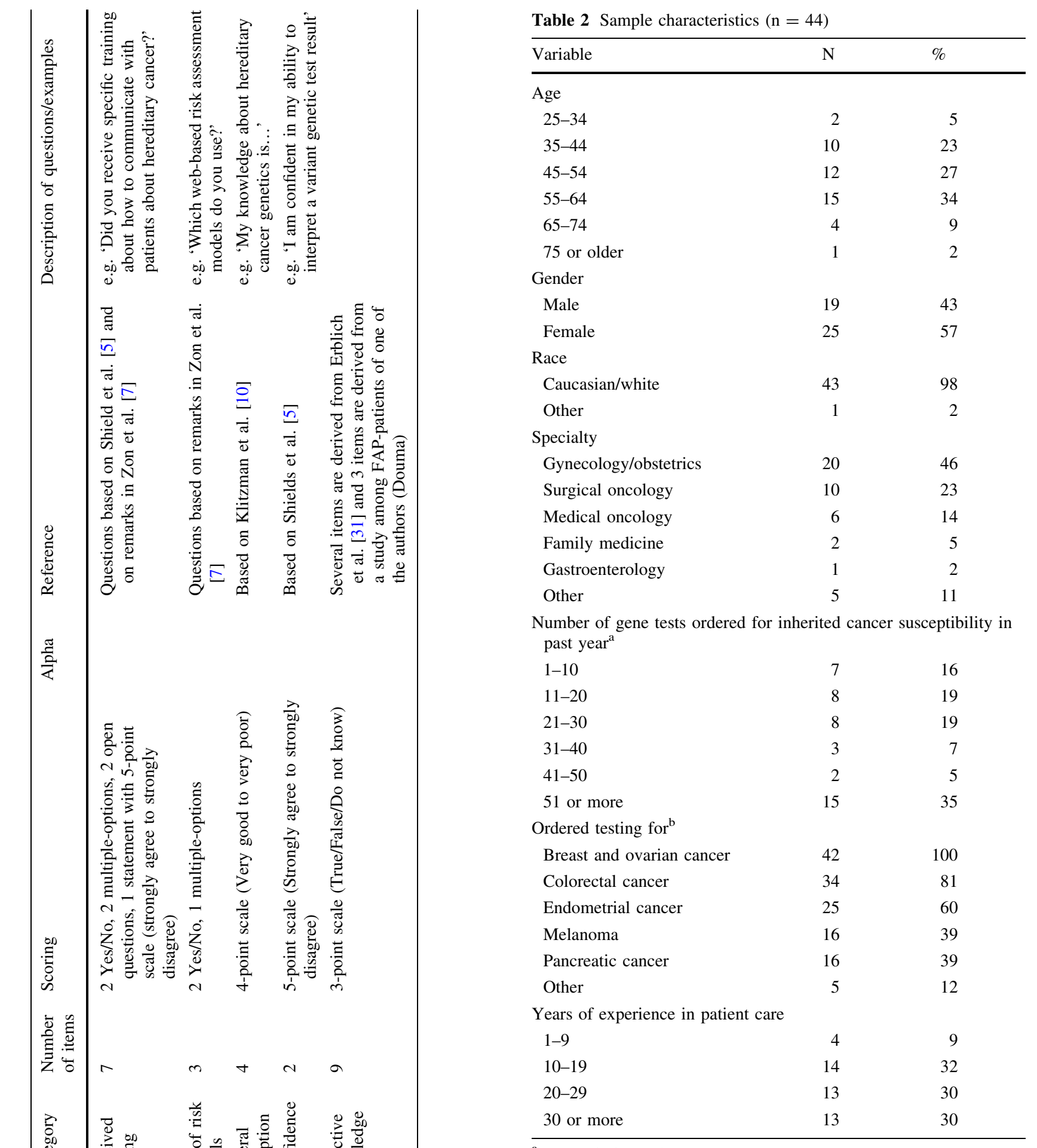

${ }^{a}$ One missing value

b Missing values are not included in the calculation of percentages. Three persons had missing values on this question

their patients, while only $2 \%(\mathrm{n}=1)$ disagreed. Furthermore, $91 \%(\mathrm{n}=40)$ agreed that it was their responsibility to remind patients about their screening, $2 \%(\mathrm{n}=1)$ neither agreed or disagreed, while $7 \%(\mathrm{n}=3)$ disagreed. 
Table 3 Adapted Ideal Patient Autonomy Scale

Item (with original item numbers)

\begin{tabular}{|c|c|c|}
\hline $\begin{array}{l}\text { (Strongly) } \\
\text { Agree }\end{array}$ & $\begin{array}{l}\text { Neither } \\
\text { agree or } \\
\text { disagree }\end{array}$ & $\begin{array}{l}\text { (Strongly) } \\
\text { Disagree }\end{array}$ \\
\hline$\%$ & $\%$ & $\%$ \\
\hline
\end{tabular}

Scale: Doctors knows best $(\alpha=0.61)$

2. It is better that the healthcare provider rather than the patient decides about genetic testing

5. During the conversation, the patient must entrust him/herself to the expertise of the healthcare provider

9. If the healthcare provider and the patient cannot agree on whether or not to undergo genetic testing, the healthcare provider should make the final decision

10. The patient should, without much information on the consequences, confidently undergo genetic testing

12. The healthcare provider can presume that the patient knows the consequences of receiving a genetic test result

Scale: Patient should decide $(\alpha=0.45)$

6. The patient must choose between whether to undergo genetic testing or not

11. It would be taking things too far when the healthcare provider would decide for the patient

$\begin{array}{rrrrrr}39 & 89 & 1 & 2 & 4 & 9 \\ 38 & 86 & 3 & 7 & 3 & 7 \\ 41 & 93 & 2 & 5 & 1 & 2 \\ & & & & & \\ 13 & 30 & 7 & 16 & 24 & 55 \\ 14 & 32 & 14 & 32 & 16 & 36 \\ 37 & 84 & 2 & 5 & 5 & 11\end{array}$

14. As it concerns the body and life of the patient, the patient should make decisions about genetic testing

Scale: Right to non-participation $(\alpha=0.42)$

4. Patients should have the right not to be involved in the decision about genetic testing

8. Patients who become afraid when deciding about genetic testing should be left in peace by the healthcare provider

13. If a patient chooses not to know anything about their genetic risk, the healthcare provider should respect this

Items not included in a subscale

1. It is my responsibility to help a patient make a decision about genetic testing ${ }^{\text {a }}$

$\begin{array}{llllll}0 & 0 & 3 & 7 & 41 & 93\end{array}$

$\begin{array}{llllll}24 & 55 & 13 & 30 & 7 & 16\end{array}$

$\begin{array}{llllll}0 & 0 & 3 & 7 & 41 & 93\end{array}$

3. If a healthcare provider and patient properly consult with each other, it does not matter who makes the final decision about genetic testing

7. Before a patient consents to genetic testing she/he should receive all information on the consequences of the test result

${ }^{\text {a }}$ Item 1 is self-developed (see Table 1$)$

Fig. 1 Decision-making communication tasks

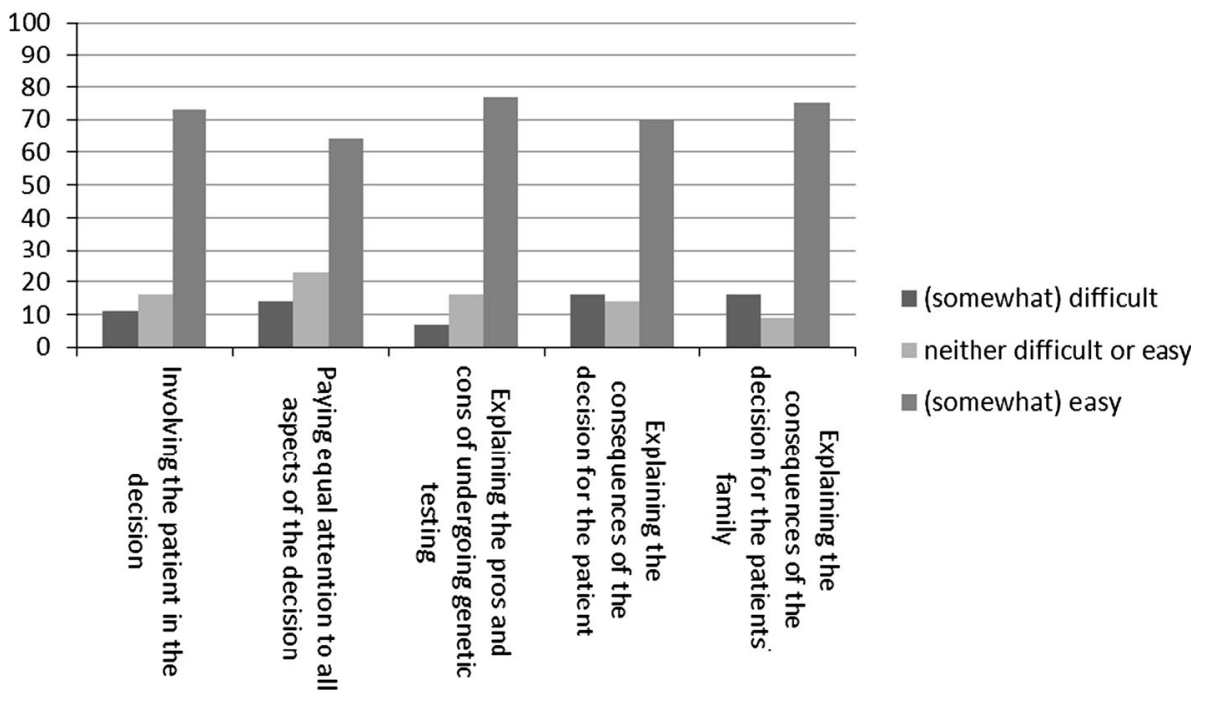


Ninety-five percent $(n=42)$ of NHGPs were optimistic that genetic research will lead to significant improvements in the treatment of complex traits, while $5 \%(\mathrm{n}=2)$ neither agreed or disagreed. Seventy-seven percent $(\mathrm{n}=34)$ agreed that personalized risk information will motivate people to change their behavior, while $18 \%$ $(\mathrm{n}=8)$ neither agreed or disagreed and $5 \%(\mathrm{n}=2)$ disagreed.

\section{Managing emotions}

Figure 2 shows that $20-36 \%$ of NHGPs perceived communication tasks related to managing emotions as difficult, depending on the task. Especially, preparing the patient for negative emotions and disentangling of emotions related to genetic testing from emotions related to the disease itself were perceived as difficult.

Seventy-one percent $(n=31)$ saw it as their responsibility to the manage emotions patients experience during genetic counseling, while $18 \%(\mathrm{n}=8)$ neither agreed nor disagreed and $11 \%(\mathrm{n}=5)$ disagreed with this. Thirtynine percent $(n=17)$ saw it as their responsibility to manage the long-term emotions ( $>3$ months) patients experience after a genetic test, while $30 \%(\mathrm{n}=13)$ neither agreed or disagreed and $32 \%(\mathrm{n}=14)$ disagreed.

\section{Education}

Fifty-five percent $(\mathrm{n}=24)$ of respondents received specific training about how to communicate with patients about hereditary cancer. This training was received either through continuing medical education (CME) (36\%), a Myriadsponsored course (29\%), fellowship training (9\%), medical school or residency $(9 \%)$ or others (such as an intensive courses on genetics; $15 \%$ ).
Participants reported to educate themselves about the most recent advances in genetic testing with CME (91\%; $\mathrm{n}=40$ ), journal articles $(84 \% ; \mathrm{n}=37)$, on genetic laboratory sponsored trainings $(55 \% ; \mathrm{n}=24)$, through colleagues $(46 \% ; \mathrm{n}=20)$ and on the job training $(41 \%$, $\mathrm{n}=18$ )

Ninety-one percent $(\mathrm{n}=40)$ felt confident about taking a cancer genetic family history [(strongly) agree], while $9 \%(\mathrm{n}=4)$ neither agreed or disagreed. Thirty-six percent $(\mathrm{n}=16)$ used web-based tools for taking a family history. Main reasons for not using these tools are time $(n=6)$, unfamiliarity $(\mathrm{n}=5)$, use a paper form $(\mathrm{n}=5)$, prefer orally discussing family history $(\mathrm{n}=3)$ and other $(\mathrm{n}=8)$. Seventy-four percent $(\mathrm{n}=31)$ used web-based risk assessment models. Of those not using web-based risk assessment tools $79 \%(\mathrm{n}=11)$ would be interested to use them.

\section{Knowledge}

Figure 3 shows that $30-61 \%$ of NHGPs judged their knowledge on genetics as very good, while 32-64\% judged it as somewhat good, depending on the specific topic.

Sixty-eight percent $(\mathrm{n}=30)$ agreed or strongly agreed that they were confident about their ability to interpret a variant cancer genetic test result, while $23 \%(\mathrm{n}=10)$ neither agreed or disagreed and $9 \%(\mathrm{n}=4)$ disagreed. Ninety-eight percent $(n=43)$ agreed or strongly agreed that they are confident about their ability to interpret a negative cancer genetic test result, while $2 \%(\mathrm{n}=1)$ neither agreed or disagreed.

The mean knowledge score was $6.5(\mathrm{SD}=1.7)$. Table 4 shows that the percentage of participants giving the correct

Fig. 2 Managing emotions

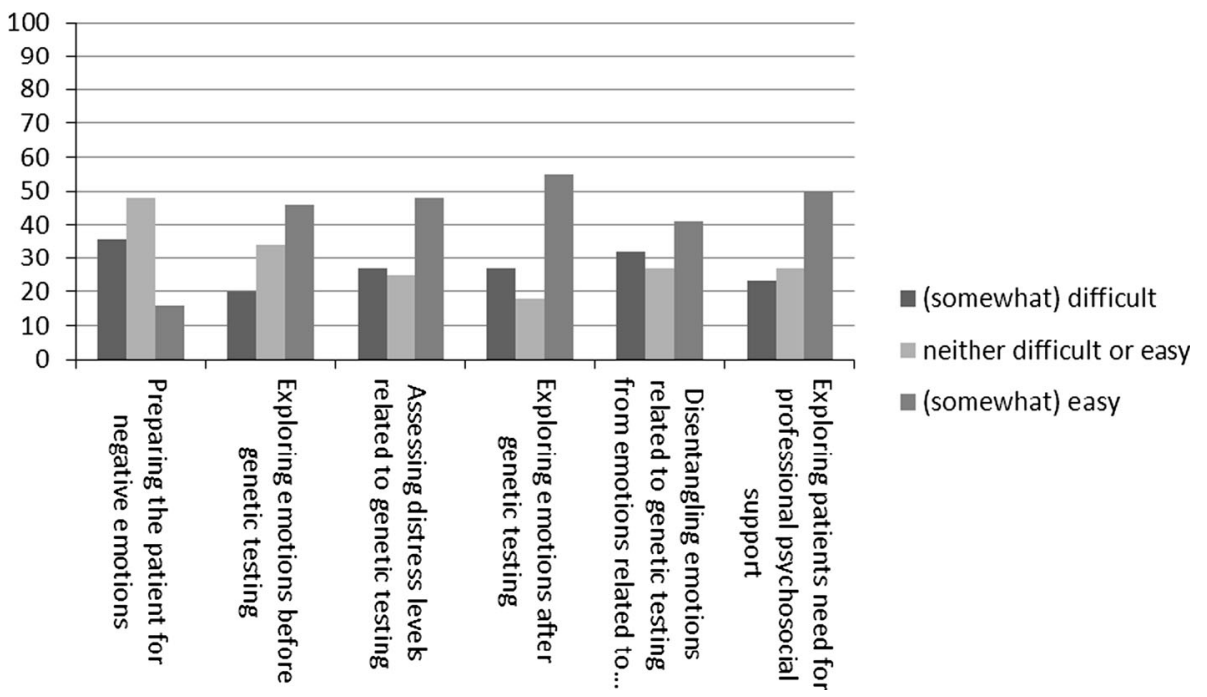


Fig. 3 Perception of own oncogenetic knowledge

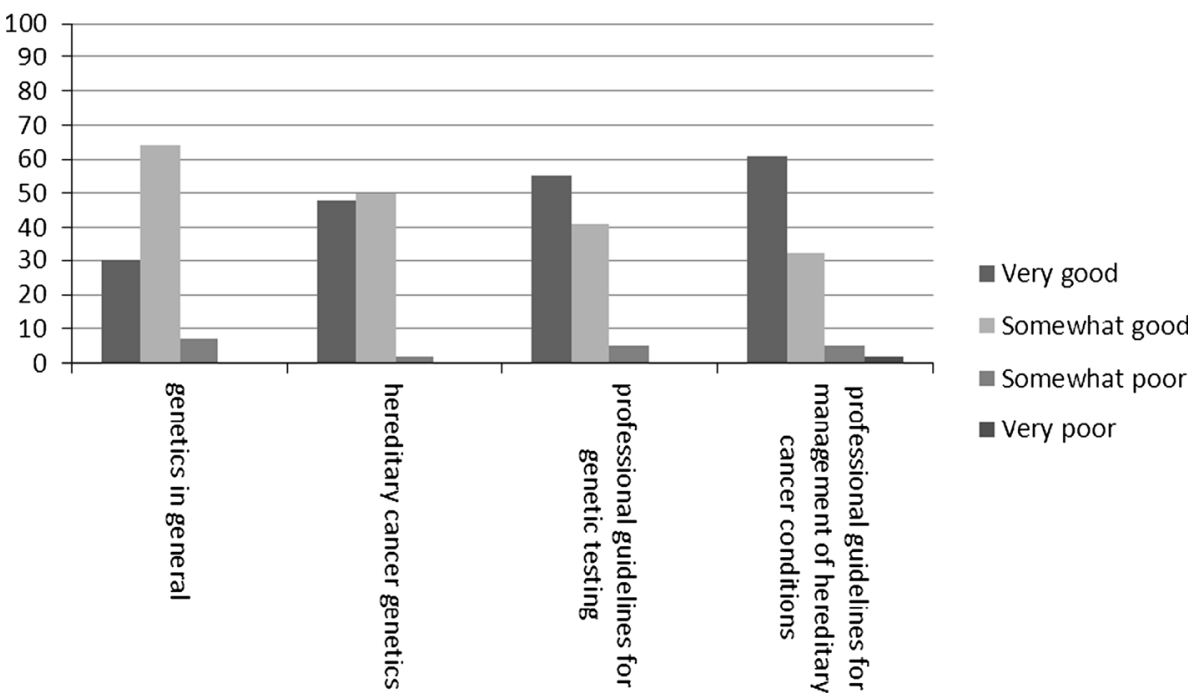

Table 4 Participants' knowledge about hereditary cancer

Statement

If a women's BRCA1 or BRCA2 gene result shows a variant of unknown significance, other affected family members 41 need to be tested in order to determine the meaning of the result. (false)

If a woman's BRCA1 or BRCA2 gene result reveals a positive test, she should be counseled to have her ovaries surgically 96 removed after she is done having children. (true)

If a father has a mutation in the APC gene (Familial adenomatous polyposis (FAP), his children have a $50 \%$ chance (1 in 80

2) for carrying this mutation as well. (true)

After removal of colon polyps for an FAP diagnosis regular bowel examinations are no longer necessary. (false) 91

A hereditary predisposition to FAP can skip a generation. (false)

If a person has colorectal cancer at age 49 and also has a family member with endometrial cancer diagnosed at age 84

60 years, genetic testing is indicated. (true)

A person with uterine cancer at 49 years of age has an indication for genetic counseling. (true)

A person with two melanomas has an indication for genetic counseling. (true)

If a female is found to have a BRCA mutation and her sister's BRCA result is negative, the sister is still at increased risk 68 for developing ovarian cancer. (false)

answer ranged between 41 and $96 \%$. Only three persons gave the correct answer to all knowledge questions.

There was a significant positive correlation between Objective knowledge and Information giving Skills perception, $\mathrm{r}_{\mathrm{s}}=.33, p=0.03$, meaning that participants with more knowledge had a more positive view on their own information giving skills.

\section{Discussion}

In contrast to known studies showing that providers are unprepared to counsel their patients [9-14], our study shows that most non-genetic health professionals ordering cancer gene testing have a positive attitude towards, knowledge of and skills in discussing and ordering genetic testing for cancer.

To be able to interpret these findings we first need to address the low response rate $(11 \%)$ of our study. Our study may have suffered from response bias, as our respondents may be those who view this as an important process whereas those who do not may not have responded. Also, our data shows that respondents were individuals with a lot of experience in ordering cancer gene testing (47\% ordering more than 30 gene tests a year) and half of them received training regarding communication with patients about hereditary cancer. These findings suggest an overrepresentation of experienced and well-trained nongenetic health professionals. If the low response rate reflects a lack of interest, this is worrisome. Those who 
may not be as comfortable with communicating informed consent may not be answering and thus it is hard to address what they specifically need for resources. Furthermore, while all individuals in the databases identified themselves as ordering genetic testing we received many returned envelopes, suggesting that these databases were not as up to date or representative as may be suggested.

So, how to interpret the positive view of NGHPs of discussing and ordering genetic tests for cancer? Especially, as the wealth of available research literature suggest that non-genetic health professionals experience difficulties in genetic counseling [9, 11, 18, 20-22]. Of note, medical specialists and primary care physicians (as in many of the other studies cited) are quite different from our NGHPs who are part of a database of providers identifying themselves as providers of genetic testing. Our respondents, with a high interest in genetic testing, might indeed have better communication skills or felt the need, because of social desirability, to at least give this impression. Future research might use observations of genetic counseling by non-genetic health professionals ordering their own genetic testing to investigate the skills of this specific group.

Our knowledge level seems to be higher than observed in most other studies where correct answers to knowledge questions regarding cancer gene testing in non-genetic health professionals ranged between 13 and $48 \%$ [13, 2325] ). In contrast, we also found a study among medical specialists showing higher levels of knowledge ranging between 72 and $100 \%$ [26]. It is however hard to compare these studies as knowledge questions are quite different in each one of them and different health professionals are included. It is important to note however, that the high degree of variability in knowledge scores could raise concern regarding accuracy of information being given to some patients. Only three respondents in our study were able to answer all knowledge questions correctly. Investigation of individual items shows that respondents know least about consequences for other family members. This might lead to family members being less well informed if people get tested through a NGHP. This definitely warrants further investigation. Also, the fact that more than $30 \%$ of participants are unsure how to interpret a variance of unknown significance (VUS) is a reason for concern, as the number of VUS will increase with the current application of next generation sequencing (NGS) in the United States.

Although most NGHPs in our study have an overall positive view, they report more difficulties managing emotions. In addition, they do not perceive management of long-term emotions as their responsibility. The majority of our respondents however are involved in long-term management of at-risk patients and should be prepared to address these emotions.
Slightly more than half of our respondents have received education regarding communication about genetic testing. The low percentage of NGHPs who received training is a reason for concern. In the last decennium genetic health professionals have moved, at least theoretically, from nondirective counseling to counseling based on principles of shared decision making [27-29]. However, NGHPs in our study still seem to have a preference for non-directive counseling in which patients decides. NGHPs may not be well informed about the benefits of shared decision making in genetic counseling.

Our study showed that the higher the knowledge level, the more confidence non-genetic health professionals reported in information giving skills. This association suggests that awareness of knowledge gaps affects health professionals' confidence. Would identifying knowledge gaps in individual NGHPs be a helpful route towards enhancing quality and consistency of care among providers performing genetic risk assessment, counselling and testing? Interestingly, Prochniaks' study suggests that confidence plays an important role in preference of physicians towards ordering genetic testing themselves or rather refer to a clinical genetic center [11]. In their study individuals who had the highest knowledge level were significantly more likely to have a preference for referral to a cancer genetics center instead of counseling the patient themselves. This suggests that knowing your limitations makes NGHPs more willing to get further education. In addition, this could also mean that they value more the contribution that genetic professionals make to the emotional aspects that arise during counseling sessions and the genetic professional expertise.

Overall, NGHPs who participated in our study have a positive view on their attitude towards, knowledge of and skills in discussing and ordering genetic testing. However, our study raises several concerns about how well-informed patients and their families will be. Specific attention is needed for the consequences of genetic testing for family members and the interpretation of VUS. Continuing medical education should address these issues.

Acknowledgments This cross-sectional questionnaire study is a collaborative effort between The Ohio State University Medical Center and the Academic Medical Center (AMC), Amsterdam, the Netherlands. Kirsten Douma is supported by a Fellowship Award from the Dutch Cancer Society (UVA 2011-4918). We thank the health professionals who participated in this study. We gratefully acknowledge the support of several research assistants.

Open Access This article is distributed under the terms of the Creative Commons Attribution 4.0 International License (http://crea tivecommons.org/licenses/by/4.0/), which permits unrestricted use, distribution, and reproduction in any medium, provided you give appropriate credit to the original author(s) and the source, provide a link to the Creative Commons license, and indicate if changes were made. 


\section{References}

1. Pilarski R (2009) Risk perception among women at risk for hereditary breast and ovarian cancer. J Genet Couns 18(4):303-312

2. Vos $\mathbf{J}$ et al (2008) The counsellees' view of an unclassified variant in BRCA1/2: recall, interpretation, and impact on life. Psychooncology 17(8):822-830

3. Lobb EA et al (2004) Communication and information-giving in high-risk breast cancer consultations: influence on patient outcomes. Br J Cancer 90(2):321-327

4. Keating NL et al (2008) Physicians' experiences with BRCA1/2 testing in community settings. J Clin Oncol 26(35):5789-5796

5. Shields AE, Burke W, Levy DE (2008) Differential use of available genetic tests among primary care physicians in the United States: results of a national survey. Genet Med 10(6): 404-414

6. Robson ME et al (2010) American Society of Clinical Oncology policy statement update: genetic and genomic testing for cancer susceptibility. J Clin Oncol 28(5):893-901

7. Zon RT et al (2009) American Society of Clinical Oncology policy statement: the role of the oncologist in cancer prevention and risk assessment. J Clin Oncol 27(6):986-993

8. de Haes H, Bensing J (2009) Endpoints in medical communication research, proposing a framework of functions and outcomes. Patient Educ Couns 74(3):287-294

9. Giardiello FM et al (1997) The use and interpretation of commercial APC gene testing for familial adenomatous polyposis. N Engl J Med 336(12):823-827

10. Klitzman R et al (2013) Attitudes and practices among internists concerning genetic testing. J Genet Couns 22:90-100

11. Prochniak CF et al (2012) Barriers to and motivations for physician referral of patients to cancer genetics clinics. J Genet Couns 21(2):305-325

12. Sifri $R$ et al (2003) Use of cancer susceptibility testing among primary care physicians. Clin Genet 64(4):355-360

13. Wideroff $\mathrm{L}$ et al (2005) Hereditary breast/ovarian and colorectal cancer genetics knowledge in a national sample of US physicians. J Med Genet 42(10):749-755

14. Wilkins-Haug L et al (2000) Obstetrician-gynecologists' opinions and attitudes on the role of genetics in women's health. J Womens Health Gend Based Med 9(8):873-879

15. Christianson CA et al (2012) The use of a family history risk assessment tool within a community health care system: views of primary care providers. J Genet Couns 21(5):652-661

16. Ozanne EM et al (2012) Bias in the reporting of family history: implications for clinical care. J Genet Couns 21(4):547-556
17. Flynn BS et al (2010) Primary care physicians' use of family history for cancer risk assessment. BMC Fam Pract 11:45

18. Bensend TA, Veach PM, Niendorf KB (2014) What's the harm? Genetic counselor perceptions of adverse effects of genetics service provision by non-genetics professionals. J Genet Couns 23(1):48-63

19. Vadaparampil ST et al (2015) Pre-test genetic counseling services for hereditary breast and ovarian cancer delivered by non-genetics professionals in the state of Florida. Clin Genet 87(5): 473-477

20. Mehnert A, Bergelt C, Koch U (2003) Knowledge and attitudes of gynecologists regarding genetic counseling for hereditary breast and ovarian cancer. Patient Educ Couns 49(2):183-188

21. Houwink EJ et al (2011) Genetic educational needs and the role of genetics in primary care: a focus group study with multiple perspectives. BMC Fam Pract 12:5

22. Nippert I et al (2011) Confidence of primary care physicians in their ability to carry out basic medical genetic tasks-a European survey in five countries-part 1. J Community Genet 2(1):1-11

23. Cremers R et al (2012) Urologists' and GPs' knowledge of hereditary prostate cancer is suboptimal for prostate cancer counseling: a nation-wide survey in The Netherlands. Fam Cancer 11(2): 195-200

24. Escher M, Sappino AP (2000) Primary care physicians' knowledge and attitudes towards genetic testing for breast-ovarian cancer predisposition. Ann Oncol 11(9):1131-1135

25. Blazer KR et al (2004) Effects of a cancer genetics education programme on clinician knowledge and practice. J Med Genet 41(7):518-522

26. van Riel E et al (2010) BRCA testing of breast cancer patients: medical specialists' referral patterns, knowledge and attitudes to genetic testing. Eur J Cancer Care (Engl) 19(3):369-376

27. Rantanen E et al (2008) What is ideal genetic counselling? A survey of current international guidelines. Eur J Hum Genet $16(4): 445-452$

28. Weil J (2003) Psychosocial genetic counseling in the postnondirective era: a point of view. J Genet Couns 12(3):199-211

29. Smets E, van Zwieten M, Michie S (2007) Comparing genetic counseling with non-genetic health care interactions: two of a kind? Patient Educ Couns 68(3):225-234

30. Stiggelbout AM et al (2004) Ideals of patient autonomy in clinical decision making: a study on the development of a scale to assess patients' and physicians' views. J Med Ethics 30(3): 268-274

31. Erblich J et al (2005) Development and validation of a Breast Cancer Genetic Counseling Knowledge Questionnaire. Patient Educ Couns 56(2):182-191 